\title{
Stability Analysis and Optimization of Wind Energy Conversion System Using Extremum Seeking Output Feedback Controller for Dynamic Wind Speed Variations
}

\author{
M.B.Hemanth Kumar' ${ }^{1}$, B.Saravanan ${ }^{1 *}$ \\ ${ }^{1}$ Power System Research Lab \\ School of Electrical Engineering \\ Vellore Institute of Technology \\ *Corresponding authorE-mail :bsaravanan@vit.ac.in
}

\begin{abstract}
Stability of power systems is an important aspect for interconnecting different renewable energy sources into the existing electrical network. The concern over environmental effects due to conventional power plant made the researchers to implement many solutions for introducing renewable energy due to their intermittent nature. When the wind energy conversion system is introduced into the grid there's need of voltage and frequency control for maintaining reactive power demand and also many issues from the consumer end and also it must satisfy the grid standards. As the wind is dynamic in nature there are issues like stability, load imbalance, power quality and other issues. In this paper, a non-linear feedback controller is introduced based on field-oriented control (FOC) approach and simulated in MATLAB environment. The designed controller is tested for wind data for examining the stability and power coefficient for the wind turbine. This controller also achieves fast transient response for rapid changes in the wind profile.
\end{abstract}

Keywords: Extremum seeking; non-linear controller; power coefficient; power system stability; renewable energy.

\section{Introduction}

Due to the usage of fossil fuel, the operation of conventional power plants has made the researchers to introduce more number of renewable energy sources into the electricity market. The power system planners also has to make sure that, there is less environmental effect due to growing lifestyle of the consumers. When concentrating on the renewable resources like wind, hydro and solar energies. Hydropower plants are completely dependent on the occurrence of monsoons and various geographical locations [1]. While coming to the solar energy it depends mostly on the irradiance and sometimes due to partial shading condition it may not be able to produce any output.

Similarly, many aspects come into picture while studying renewable energies and their integration into the electrical network. But the concept of wind energy is better than other sources due to its high potential output and environmentally friendly and also for meeting the local loads with fewer transmission losses. For the wind energy conversion system, a wind turbine will be employed that rotates according to the wind directions and this later coupled to induction generator which is most commonly used machine for converting mechanical energy into electrical energy through a gear box. The necessity of a gear box is to increase the number of revolutions of the generator than that of the wind turbine.

Nowadays many types of generators are present and among them, squirrel induction generators are mostly preferred because of its robustness, less investment, and ease of controlling the system. One should remember that wind turbine does not have any role in controlling voltage and frequency regulation whenever a disturbance has been reported in the network such as faults. The term power system stability is defined as the ability of the power system to maintain synchronism with the externally connected load when it is subjected to any disturbance in the form of faults may be transient or sustained faults [2], [3].

In other sense, it is necessary to achieve stable voltage and synchronize with the externally connected load when it is subjected to disturbances in the form of faults. A power system is a large interconnected network with a huge number of power electronic devices having nonlinear characteristics [4]. In such scenario, it becomes very difficult to study the stability of the power system and the characteristics of those devices.

It has been stated in [5] the instability occurs in the range of 0.1 to $10 \mathrm{~Hz}$ and the constrains like flux, generator speed, excitation system, rotor angle, turbine mechanical system are studied. The power electronic devices that are responsible for the instability of the system are also mentioned with differential equations in [6]. The instability occurs either due to changes in the load or wind speed variations. In this aspect, many researchers have modeled several controlling techniques for SCIG to improve the stability of the system. Their main objective is to model and develop a better controller for determining the reference signals. When compared to linearized system model [7]-[9] which are simple, robust and reliable the wind turbine modeling being a nonlinear structure usually suffers from system uncertainties. There are several algorithms which are implemented in conjunction with the controllers will outperform other ideal feedback controllers.

A fuzzy logic based approach is used for improving the WECS performance is shown in [10], [11], and the combination of fuzzy logic with matrix converter consisting of the four-leg model is presented in[12] for improving the efficiency. Some of the controller designs depend on system model and some other are model 
independent designs. In the aforementioned model dependent case we have to remodel the controller and redesign the system parameters for different wind turbine models to determine the performance of the power system[13]. Few controller design presented in [6], [14], [15] are similar to the present work but some assumptions based on system performance, field oriented control for dynamic modeling are proposed. It's very important to note that the wind turbine output power must stay in the bounded region though there are wind speed variations.

In this paper, a nonlinear controller is designed for compensating the modeling errors with reference to feedback linearization technique for stabilizing the power system [13].Here the controller is tested for wind speed without any disturbance and with disturbance to examine the wind turbine model stability[16]. In order to improve the system transient response, we propose a feedback controller on field oriented control approach(FOC)[17], [18]. The frequency and the stator voltage of SCIG are controlled through matrix converter to obtain desired closed loop performance.

The paper is organized as follows. Wind energy conversion system modeling is shown in section II. Modeling of SCIG in stator reference frame including wind turbine model is presented in section III. Later nonlinear controller with feedback is discussed in section IV. Simulation results are shown in section V and conclusions are presented in section VI.

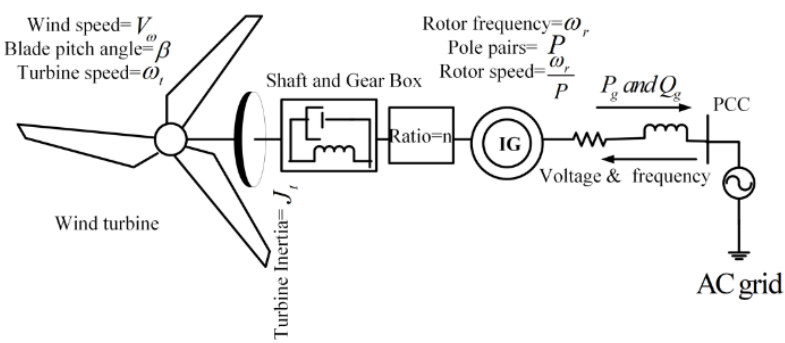

Fig. 1: Model diagram for wind energy conversion system connected to grid

\section{Wind energy conversion system}

A simple wind turbine connected to grid through PMSG generator is shown in Figure1. The mechanical power produced by the wind turbine [19]-[21] is due to the interaction of the wind flow over the turbine blade and is given by the expression as

$$
P_{\omega}=0.5 \rho \mathrm{AV}_{\omega}^{3} ; \mathrm{A}=\pi \mathrm{r}^{2}
$$

Here $P_{\omega}$ is the mechanical power obtained from the wind $\rho$ is the density of the air in $\left(\mathrm{Kg} / \mathrm{m}^{3}\right)$ where the wind turbine is located and it varies according to climatic conditions.

A is the total area swept by the turbine blades in $\left(\mathrm{m}^{3}\right)$ and $r$ is the radius of the rotor in $(\mathrm{m})$

$V_{\omega}$ is the wind velocity in $(\mathrm{m} / \mathrm{s})$

When the wind hits the turbine blades, it produces turbine power $\left(P_{\mathrm{t}}\right)$ and rotates turbine with a speed of $\left(\omega_{\mathrm{t}}\right)$, due to this there induces a turbine torque of $\left(T_{\mathrm{t}}\right)$ given by the expression

$$
T_{t}=P_{t}\left(\omega_{t}, v_{\omega}\right) \frac{1}{\omega_{t}}=P_{\omega} C_{p}(\omega, v \omega)
$$

From the above expression, we can derive for turbine power[22] as

$$
P_{t}\left(\omega_{t}, v_{\omega}\right)=14.33 v_{\omega}^{3} \frac{\left(\frac{151}{\lambda_{c}}-0.58 \delta-0.002 \delta^{2.14}-13.2\right)}{\exp \left(18.4 \frac{1}{\lambda_{c}}\right)}
$$

So it is clear from equation (3) that turbine power produces is a function of wind speed $V_{\omega}$ and also $\lambda_{c}$ which is defined as tip speed ratio. The tip speed ration is defined as the ratio between rotor blade speed at the tip to the wind velocity and is given by

$\lambda_{c}=\left(\frac{1}{\lambda-0.002 \delta}-\frac{0.003}{\delta^{3}+1}\right)^{-1}$

In equation (2) $\mathrm{Cp}$ gives the expression for the efficiency of the aerodynamic system, as per betz limit power coefficient value $\mathrm{Cp}$ is equal to 0.590 but practically its value ranges between 0.2 to $0.4[12],[23]-[26]$. For the purpose of simulation analysis, we go for the approximate equation of power coefficient and it is given as follows

$$
C_{p}\left(v_{\omega}, \omega_{t}\right)=0.73 \frac{151 \frac{v_{\omega}}{R \omega_{t}}-13.635}{\exp \left(\frac{v_{\omega}}{R \omega_{t}}-0.003\right)}
$$

From equation (5) power coefficient value depends on turbine speed and we can utilize this speed for stability, power optimization, and power control. The controller must operate the wind turbine for stability improvement under fluctuating wind conditions through proper feedback controller and maintain the power coefficient at its maximum. The variation in the power coefficient $\left(C_{p}\right)$ for different turbine speed $\left(\omega_{t}\right)$ with wind speed changes is shown in Figure 2 and we can interpret that the maximum value always maintained at $\left(\mathrm{C}_{\mathrm{p}}\right)=0.4$.

As we mentioned that the turbine power depends on mechanical power developed, the variation of turbine power to change in turbine speed at different wind speed is plotted in Figure 3.

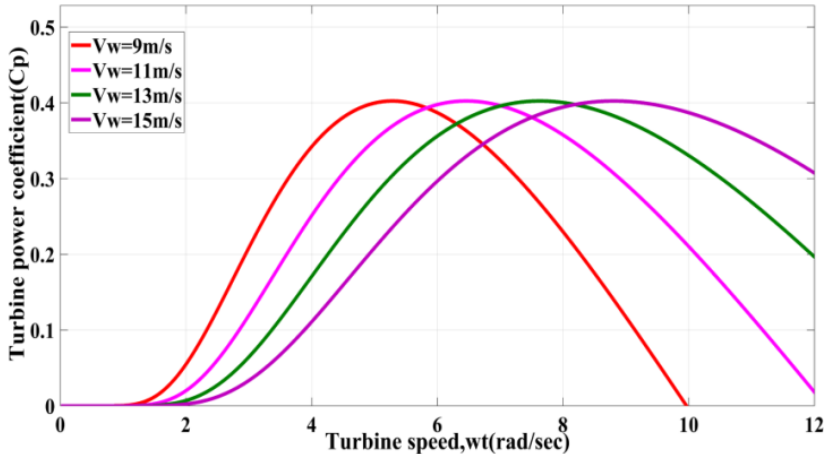

Fig. 2: Variation of power coefficient for different wind speed variation of turbine speed

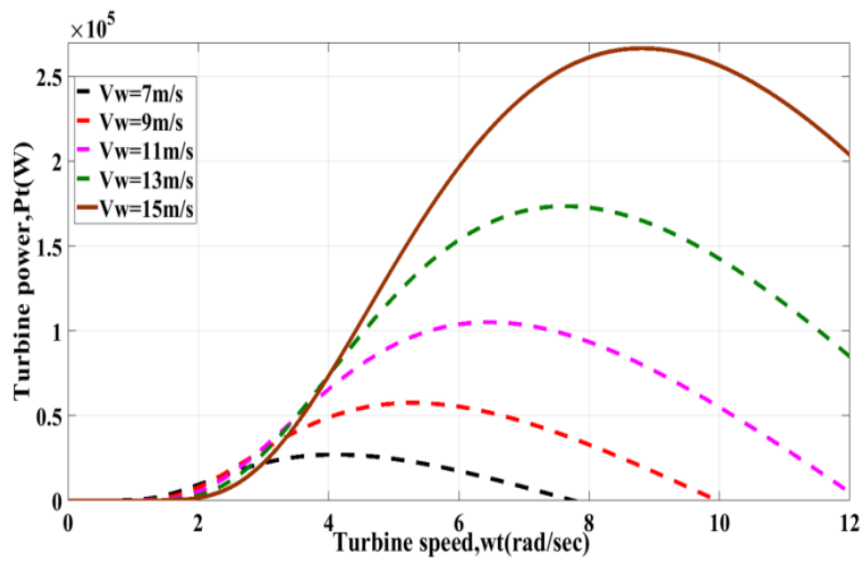

Fig.3: Variation of turbine power with turbine speed at different wind velocity 


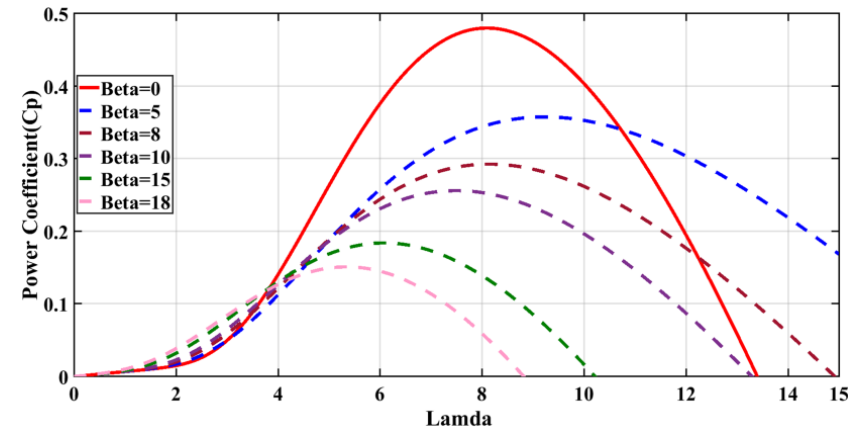

Fig. 4: Power coefficient characteristics for different values of $\lambda, \beta$

As mentioned earlier power coefficient is a function of tip speed ration and pitch angle and its characteristics are shown in Figure 4.

\section{Induction generator and wind turbine mod- eling}

The most preferred generator for wind energy conversion system is the squirrel cage type due to robust construction, low-cost maintenance, precise torque control and comparatively economical [27]-[29]. With the application of vector control technique, it is possible for getting better control of wind turbine when connected to induction generator for dynamic wind conditions.

the wind turbine dynamic model consisting of shaft and gearbox are given by

$$
\begin{aligned}
& \frac{\mathrm{d}}{\mathrm{d} t} \theta=\omega_{t}-\frac{1}{g p} \omega_{r} \\
& \theta=\theta_{t}-\frac{1}{g P} \theta_{r} \\
& \frac{d}{d t} \omega_{t}=-\frac{P_{t}\left(\omega_{t}, v_{\omega}\right)}{J_{t} \omega_{t}}-T \frac{1}{J_{t}}
\end{aligned}
$$

here $\omega_{r}$ gives the electrical angular frequency of the induction generator

$\theta_{t}$ represents the wind turbine angular position

Similarly $\theta_{r}$ is the IG rotor angle in electrical degrees

$p$ are IG pole pairs and $g$ the gear box ratio

$T=\frac{1}{J_{t}}\left\{D_{r}\left(\omega_{t}-\frac{\omega_{r}}{g p}\right)+Q_{s} \theta\right\}$

$\mathrm{J}_{\mathrm{t}}$ is wind turbine inertia

$\mathrm{D}_{\mathrm{r}}$ is damping factor of the turbine

$\mathrm{T}$ is the load torque due to the shaft and is given by

$\mathrm{Q}_{\mathrm{s}}$ is the stiffness coefficient

The scig modeling in stator reference frame [9] is as follows

$$
\begin{aligned}
& \frac{\mathrm{d}}{\mathrm{d} t} i_{\alpha}=-D_{0} i_{\alpha}+D_{1} \phi_{\alpha}+D_{2} \omega_{r} \phi_{\beta}+v_{\alpha} \frac{1}{\mu L_{s}} \\
& \frac{\mathrm{d}}{\mathrm{d} t} i_{\beta}=-D_{0} i_{\beta}+D_{1} \phi_{\beta}-D_{2} \omega_{r} \phi_{\alpha}+v_{\beta} \frac{1}{\mu L_{s}}
\end{aligned}
$$

Here

$$
\eta=p D_{r} \frac{1}{g J}\left(\omega_{t}-\frac{1}{g p} \omega_{r}\right)-\frac{1}{g J} p Q_{s} \theta
$$

In the above equation $i_{\alpha}$ and $i_{\beta}$ are the stator currents in

$(\alpha, \beta)$ reference frame

$\phi_{\alpha}$ and $\phi_{\beta}$ are the fluxes corresponding to the rotor of the scig

$v_{\alpha}$ and $v_{\beta}$ gives the stator voltage

$L_{s}=L_{l s}+L_{m}$ stator circuit inductance,

$L_{r}=L_{l r}+L_{m}$ rotor circuit inductance

Now the electromagnetic torque produced by the induction generator is given by the expression as follows

$T_{e}=1.5 p \frac{L_{m}}{L_{r}}\left(i_{\beta} \phi_{\alpha}-i_{\alpha} \phi_{\beta}\right)$

here Lm gives the mutual inductance value, all the parameter values are given in the appendix.

The electrical angle can also be written as

$\theta_{o}=\int_{0}^{t} \omega_{0} \mathrm{~d} \tau$

As the modeling is performed in $(\alpha, \beta)$ the output voltages must be transformed to the stationary reference frame and from this, the current supplied to the grid can be easily calculated based on stator current.

The corresponding transformed variables for three phase to two phase is given by

$\left[\begin{array}{l}v_{\alpha} \\ v_{\beta}\end{array}\right]=\left[\begin{array}{ll}V_{\mathrm{om}} & \cos \theta_{0} \\ V_{\mathrm{om}} & \sin \theta_{0}\end{array}\right]$

From the above equations of $\theta, \omega_{t}, i_{\alpha}, \omega_{r}, \theta_{0}$, the WECS dynamics can be summarized as follows

$$
\frac{\mathrm{d}}{\mathrm{dt}} \theta=\omega_{t}-\frac{1}{g p} \omega_{r}
$$

$\frac{\mathrm{d}}{\mathrm{d} t} \omega_{r}=1.5 p^{2} L_{m} \frac{1}{L_{r} J}\left(i_{\beta} \phi_{\alpha}-i_{\alpha} \phi_{\beta}\right)-\eta$

$$
\frac{\mathrm{d}}{\mathrm{d} t} \omega_{t}=-P_{t}\left(\omega_{t}, v_{\omega}\right) \frac{1}{J_{t} \omega_{t}}-\phi \frac{1}{J_{t}}
$$


$\frac{\mathrm{d}}{\mathrm{d} t} \Phi_{o p}=\omega_{o p}$

$\frac{\mathrm{d}}{\mathrm{d} t} i_{\alpha}=-D_{0} i_{\alpha}+D_{1} \phi_{\alpha}+D_{2} \omega_{r} \phi_{\beta}+\frac{V_{o m}}{\mu L_{s}} \cos \Phi_{o p}$

$\frac{\mathrm{d}}{\mathrm{d} t} i_{\beta}=-D_{0} i_{\beta}+D_{1} \phi_{\beta}-D_{2} \omega_{r} \phi_{\alpha}+\frac{V_{o m}}{\mu L_{s}} \sin \Phi_{o p}$

$\frac{\mathrm{d}}{\mathrm{d} t} \phi_{\alpha}=-\omega_{r} \phi_{\beta}+D_{3} i_{\alpha}-D_{4} \phi_{\alpha}$

$\frac{\mathrm{d}}{\mathrm{d} t} \phi_{\beta}=\omega_{r} \phi_{\alpha}+D_{3} i_{\beta}-D_{4} \phi_{\beta}$

Here $\omega_{o p}$ and $V_{o m}$ are electrical angle and voltage amplitudes

\section{Controller design}

The WECS stability analysis and control techniques are much complex and the interaction of such system needs economical and accuracy so the controller should be easy to utilize such tools for simulation study.

Here in the proposed method, the controller can be implemented for few KW to MW range of variable speed wind energy conversion system. The controller which we are designing must able to change the electromagnetic torque nearly equal to the reference torque for various drives. For induction machines field oriented controller is used for adjusting the position and speed of the drive systems.

In [30] the conventional controller are used for designing the system based on nonlinear parameters due to the transients caused by the flux as assumed that the turbine speed $\omega_{t}$ will be a linear parameter and they are couples to each other. Now by using a nonlinear controller with closed loop approach the parameters are decoupled and it is a simple technique compared to [30].

An additional parameter (u2) and an integrator is introduced to decouple the wind energy conversion system dynamic parameters. The dynamic equations for the controller are characterized as $\frac{d}{d t} y=f(y)+h_{1} u_{1}+h_{2} u_{2}+b \varepsilon, y \in \mathrm{R}^{9}, u \in \mathrm{R}^{2}$

$$
f(y)=\left[\begin{array}{c}
\omega_{t}-\frac{1}{g p} \omega_{r} \\
1.5 p^{2} L_{m} \frac{1}{L_{r} J}\left(i_{\beta} \phi_{\alpha}-i_{\alpha \phi_{\beta}}\right)-\eta \\
-P_{t}\left(\omega_{t}, v \omega\right) \frac{1}{J_{t} \omega_{t}}-\phi \frac{1}{J_{t}} \\
-D_{0} i_{\alpha}+D_{1} \phi_{\alpha}+D_{2} \omega_{r} \phi_{\beta}+\frac{V_{o m}}{\mu L_{s}} \cos \Phi_{o p} \\
-D_{0} i_{\beta}+D_{1} \phi_{\beta}-D_{2} \omega_{r} \phi_{\alpha}+\frac{V_{o m}}{\mu L_{s}} \sin \Phi_{o p} \\
0 \\
0 \\
-\omega_{r} \phi_{\beta}+D_{3} i_{\alpha}-D_{4} \phi_{\alpha} \\
\omega_{r} \phi_{\alpha}+D_{3} i_{\beta}-D_{4} \phi_{\beta}
\end{array}\right]
$$

$$
h_{1}=\left[\begin{array}{lllllllll}
0 & 0 & 0 & 0 & 0 & 1 & 0 & 0 & 0
\end{array}\right]^{T}
$$

$h_{2}=\left[\begin{array}{lllllllll}0 & 0 & 0 & 0 & 0 & 0 & 1 & 0 & 0\end{array}\right]^{T}$

$y=\left[\begin{array}{lllllllll}\theta & \omega_{r} & \omega_{t} & i_{\alpha} & i_{\beta} & V_{o m} & \Phi_{o p} & \phi_{\alpha} & \phi_{\beta}\end{array}\right]^{T}$

here $v_{1}$ is the stator electrical frequency, $v_{2}$ is the auxiliary input. The aim to achieve the decoupling between the rotor flux and electromagnetic through field-oriented control technique two variable are introduced i.e. wind turbine speed and flux magnitude as the output measurable quantities. For stability and power coefficient improvement, a feedback linearization has been applied with changes in WECS dynamics. The field-oriented control is shown in Figure 5 which generated the switching pulses for converter which further connected to the grid.

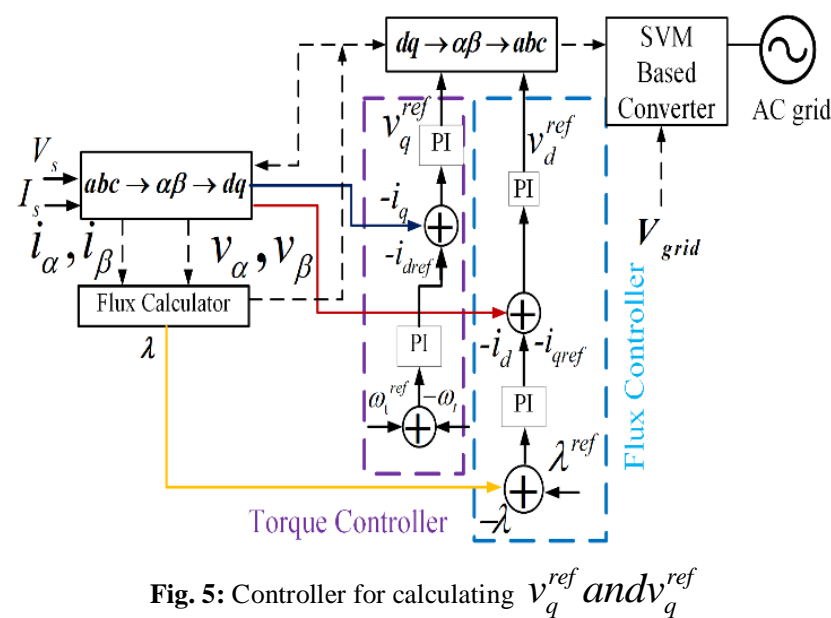

Let

$\chi_{1}=y_{1}=\omega_{t}$

$\chi_{2}=\dot{\chi}_{1}=\dot{y}_{1}=-D_{9}\left(\omega_{t}-\frac{\omega_{r}}{g p}\right)-D_{8} \theta_{o p}-\frac{T_{t}}{J_{t}}$

$\chi_{3}=\dot{\chi}_{2}=\frac{D_{5} D_{9}}{g p}\left(i_{\beta} \phi_{\alpha}-i_{\alpha} \phi_{\beta}\right)+\left(\frac{D_{8}}{D_{9}}+\frac{D_{7}}{g p}-D_{9}\right) \chi_{2}$

$+\frac{D_{8}^{2}}{D_{9}} \theta_{o p}+\left(\frac{D_{8}}{D_{9}}+\frac{D_{7}}{g p}\right) \frac{T_{t}}{J_{t}}-\frac{\dot{T}_{t}}{J_{t}}$

$\chi_{4}=\dot{\chi}_{3}=m_{4} \chi_{3}+m_{5} \chi_{2}+m_{6} \theta_{o p}-\frac{m_{0}}{\mu L_{s}} V_{o m} \phi_{\beta}$

$-\omega_{r}\left(m_{7} \phi+m_{8} \ell_{2}\right)+m_{9} \frac{T_{t}}{J_{t}}+m_{10} \frac{\dot{T}_{t}}{J_{t}}-\frac{\ddot{T}_{t}}{J_{t}}$

$\chi_{5}=\phi=\ell_{1}$

$\chi_{6}=\dot{\chi}_{5}=2\left(\phi_{\alpha} \dot{\phi}_{\alpha}+\phi_{\beta} \dot{\phi}_{\beta}\right)=2\left(y_{7} f_{7}+y_{8} f_{8}\right)$

$\chi_{7}=\dot{\chi}_{6}=2\left(\begin{array}{c}f_{8}^{2}+f_{9}^{2}+D_{3} \phi_{\alpha} f_{8}+D_{4} \phi_{\beta} f_{9} \\ -\phi_{\alpha} \phi_{\beta} f_{2}-\phi_{\alpha} \omega_{t} f_{9}+D_{3} \phi_{\beta} f_{5} \\ -D_{4} \phi_{\beta} f_{9}+\phi_{\alpha} \phi_{\beta} f_{2}+\omega_{r} \phi_{\beta} f_{4}\end{array}\right)$ 


$$
\begin{aligned}
& \chi_{8}=\dot{\chi}_{7}=G_{1}+2\left(D_{3} \phi_{\alpha} f_{6}+\omega_{r} \phi_{\beta} f_{6}\right) u_{1} \\
& +2\left(D_{3} \phi_{\beta} f_{6}\right) u_{2}=\theta \\
& \chi_{9}=\dot{\chi}_{8}=f_{1} \\
& \varphi=\arctan \left(\frac{\phi_{\beta}}{\phi_{\alpha}}\right) \\
& V_{o m}=\sqrt{v_{\alpha}^{2}+v_{\beta}^{2}}
\end{aligned}
$$

The feedback controller is shown in Figure 6 below

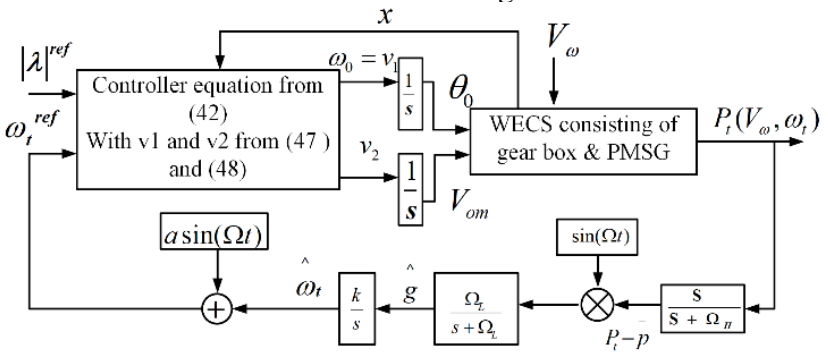

Fig. 6: Feedback Controller block for WECS

The variables are changed and results as follows

$$
\begin{aligned}
& \dot{\chi}_{4}=G_{2}+\frac{m_{0} \phi_{\alpha}}{\mu L_{s}} V_{o m} u_{1}-\frac{m_{0} \phi_{\beta}}{\mu L_{s}} u_{2} \\
& G_{1}=-m_{11} \ell_{3}+m_{12} \ell_{2}+m_{13} f_{2}(y)\left(i_{\beta} \phi_{\alpha}-i_{\alpha} \phi_{\beta}\right) \\
& G_{2}=m_{4} \chi_{4}+m_{5} \chi_{3}-\frac{m_{6}}{D_{9}} \chi_{2}-\frac{D_{8} m_{6}}{D_{9}} \theta-\frac{m_{0} V_{o m}}{\mu L_{s}}
\end{aligned}
$$

Now after a step change the variables are summarized as follows

$$
\dot{\xi}=A \xi+B \varepsilon+C V
$$

$$
\xi \in \mathrm{R}^{7}=\left[\xi_{1}, \xi_{2}, \xi_{3}, \xi_{4}, \xi_{5}, \xi_{6}, \xi_{7}\right]^{T} ; V \in \mathrm{R}^{2}=\left[\begin{array}{c}
V_{1} \\
V_{2}
\end{array}\right]
$$$$
V_{1}=-k_{1} \xi_{1}-k_{2} \xi_{2}-k_{3} \xi_{3}-k_{4} \xi_{4}
$$

$V_{2}=-k_{5} \xi_{5}-k_{6} \xi_{6}-k_{7} \xi_{7}$

The values from $\mathrm{k} 1$ to $\mathrm{k} 7$ are the gain values and they are selected for stabilizing the system.

Now due to unbounded parameter $\varepsilon$ the nonlinear control system is represented as

Let $V=-k \xi$

Now rewriting the above equation, we get

$$
\dot{\xi}=(A-C K) \xi+B \varepsilon
$$

Assume

$$
\bar{A}=A-C K
$$

Then

$$
\dot{\xi}=\bar{A} \xi+B \varepsilon
$$

For a homogeneous system we take $\mathrm{B}=0$ and the modified equation is shown below

$$
\dot{\xi}=\bar{A} \xi
$$

And integration of equation (51) between $t_{0}$ to $t$ we get

$$
\xi(t)=e^{\bar{A}\left(t-t_{0}\right)} c\left(t_{0}\right)
$$

The system is asymptotically stable only when the eigen values of matrix $\bar{A}$ satisfies Real $\lambda(\bar{A})<0$

And the equation (50) has the solution in the form as shown below

$$
\xi(t)=e^{\bar{A}\left(t-t_{0}\right)} \xi\left(t_{0}\right)+\int_{t_{0}}^{t} B \varepsilon e^{\bar{A}(t-t)} d \tau
$$

\section{Simulation results and discussion compare with and without controller}

The robust nonlinear controller with an effective feedback loop is implemented and is a new approach for decoupling input-output in order to improve the system performance. Whatever the controller we are designing, the aim is to make the system perform in a stable manner without losing stability. The stability and power coefficient improvement of WECS is studied by testing wind data [31] The Figure 7 shows the wind speed variation with time and corresponding wind turbine power is shown in Figure 8 and power coefficient is presented in Figure 9.

The variables for dynamic analysis of WECS, xetal shows a stable response for wind speed uncertainties is shown in Figure 10 and it is completely bounded. Some of the stability governing variables zeta 2 which is the power angle of the turbine and zeta 3 gives the zero dynamics as derived in wind turbine modeling are stable and some of the stability indices are shown below.

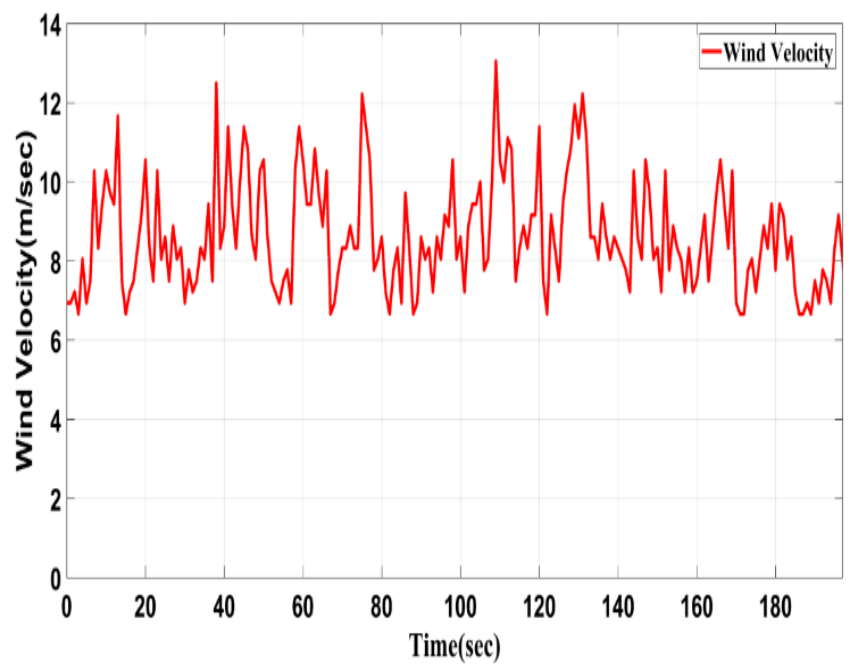

Fig. 7: Variation of wind velocity with time 


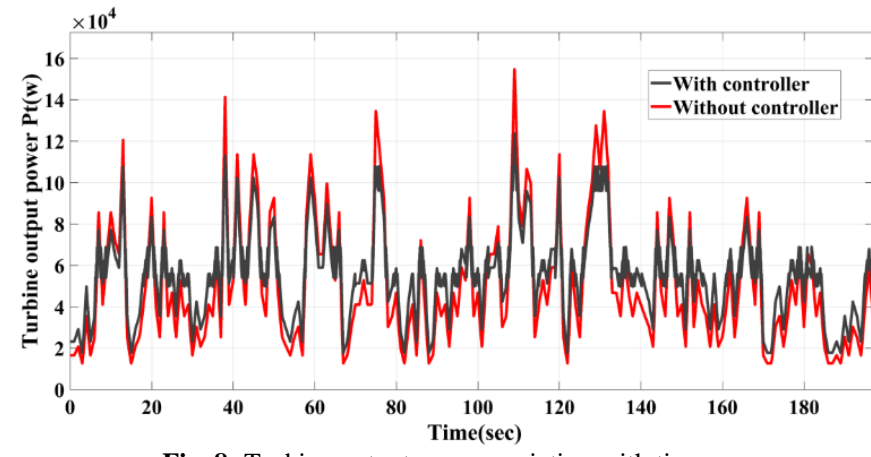

Fig. 8: Turbine output power variation with time

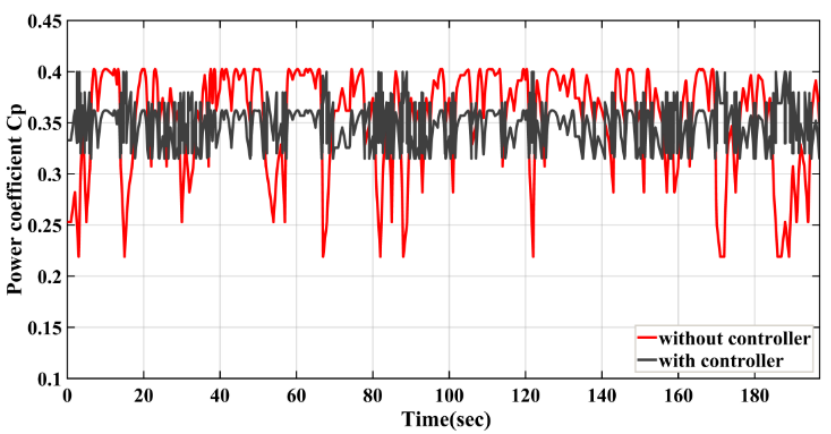

Fig. 9: Power coefficient with and without feedback controller

The steady state variables xeta1 to xeta 3 are shown in Figure 10 to Figure 12 and the solution is stable and the performance is efficient for wind speed uncertainties. For deciding whether system is stable or not the wind turbine modeling should be validated and for this we are validating this with the MATLAB/ simulink for HAWT. For improving system stability and performance the controller complexity is ignored. By selecting an appropriate gain value in equation $(47,48), v_{1}$ and $v_{2}$ desired closed loop performance can be obtained. By locating the pole the response time for this closed loop control system is much faster compared to open loop. For the wind speed shown in Figure 7 when applied to the designed controller the power coefficient is maintained close to $\mathrm{Cp}^{*}$ for an instantaneous change in the wind speed. From Figure 9 the power coefficient stays away from $\mathrm{Cp}^{*}$ without the controller and by introducing feedback loop controller the power coefficient is maintained at $\mathrm{Cp}^{*}$ which shows the robustness of the controller designed. The proposed controlled can alleviate such problem by maintaining better stability through FOC control by decoupling input-output parameters. As the WECS are installed for long-run period a small improvement in the power coefficient can guarantee high power extraction thereby reducing environmental concerns on conventional power plants.

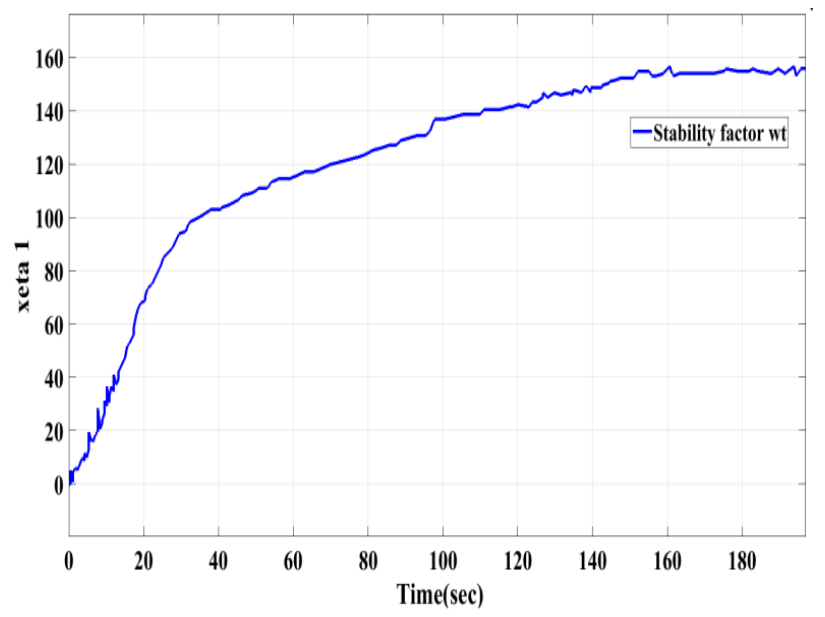

Fig. 10: Tturbine speed stability factor xeta $1\left(\omega_{t}\right)$

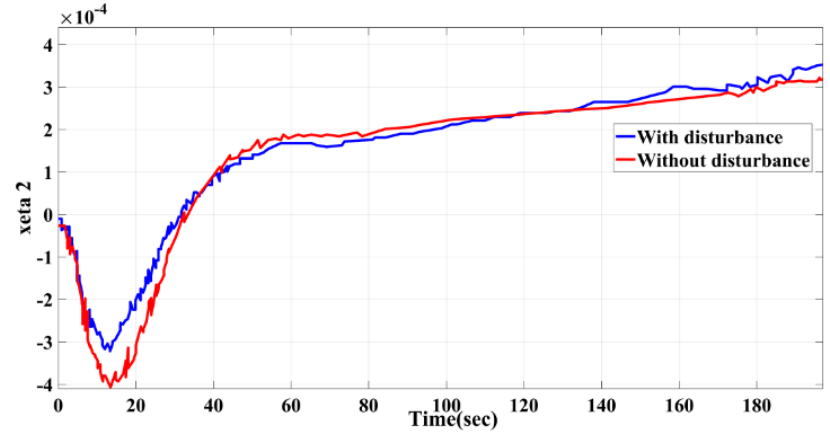

Fig. 11: Wind turbine stability index xeta 2 with and without controller

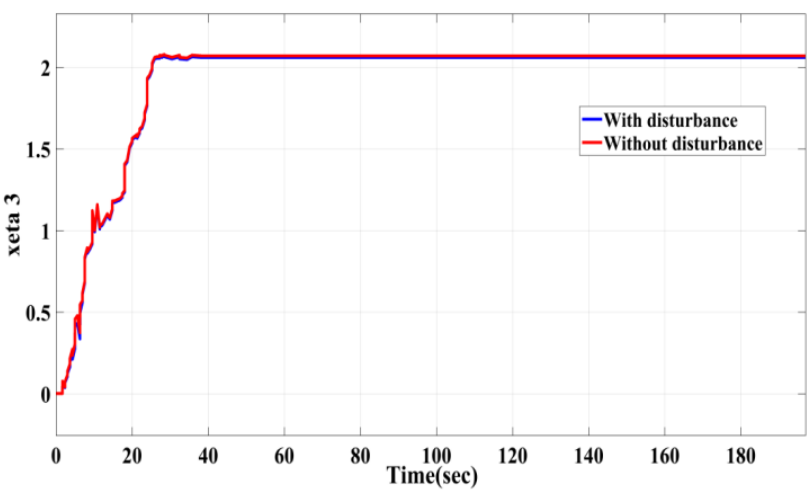

Fig. 12: Turbine stability index xeta 3 with and without controller

\section{Conclusion}

In this paper a wind turbine mathematical modeling has been performed and a nonlinear feedback controller is introduced and simulated with MATLAB tool for obtaining better stability under wind disturbances. The nonlinear feedback is designed based on field-oriented control and the controllable parameters are optimized. Among various parameters, voltage and frequency are the important parameters that must be adjusted every time whenever the wind velocity varies. This controller also overcomes the magnetic saturation of the induction machine and prevents the machine from getting damaged under disturbances in the form of wind speed variations. The proposed technique is implemented for horizontal axis wind turbine and it shows better performance for different wind speed regimes.

\section{Acknowledgements}

We acknowledge the use of data provided by NARL through www.narl.gov.in

\section{References}

[1] M. B. Hemanth Kumar and B. Saravanan, (2017), Impact of global warming and other climatic condition for generation of wind energy and assessing the wind potential for future trends. Innov. Power Adv. Comput. Technol. i-PACT 2017, pp. 1-5.

[2] J. J. Justo and R. C. Bansal, (2018), Parallel R-L configuration crowbar with series R-L circuit protection for LVRT strategy of DFIG under transient-state. Electr. Power Syst. Res., vol. 154, pp. 299-310.

[3] M. B. Hemanth Kumar and B. Saravanan,(2017), An improved resonant fault current limiter for distribution system under transient conditions,. Int. J. Renew. Energy Res., vol. 7, no. 2, pp. 547-555.

[4] A. Milczarek, M. Malinowski, and J. M. Guerrero, (2015), Reactive Power Management in Islanded Microgrid - Proportional Power Sharing in Hierarchical Droop Control. IEEE Trans. Smart Grid, vol. 6, no. 4, pp. 1631-1638.

[5] Y. Kazachkov,(2003) , Modeling wind farms for power system stability studies. Power Eng. ..., pp. 1526-1533. 
[6] M. Moechtar, T. C. Cheng, and L. Hu, (1995), Transient stability of power system-a survey. WESCON/'95. Conf. Rec. 'Microelectronics Commun. Technol. Prod. Qual. Prod. Mob. Portable Power Emerg. Technol., p. 166.

[7] M. K. Das, S. Chowdhury, and S. P. Chowdhury, (2010), Protection and voltage control of DFIG wind turbines during grid faults. IET Int. Conf. Dev. Power Syst. Prot., no. 1, pp. 24-24.

[8] A. O. Zue and A. Chandra, (2009), State feedback linearization control of a grid connected photovoltaic interface with MPPT. Electr. Power Energy Conf. (EPEC), IEEE, pp. 1-6.

[9] M. Idan and D. Lior, (2000), Continuous variable speed wind turbine: transmission concept and robust control. Wind Eng., vol. 24, IEE, pp. 151-167.

[10] A. Z. Mohamed, M. N. Eskander, and F. A. Ghali, (2001), Fuzzy logic control based maximum power tracking of a wind energy system. Renew. Energy, vol. 23, no. 2, pp. 235-245.

[11] A. M. Eltamaly and H. M. Farh, (2013), Maximum power extraction from wind energy system based on fuzzy logic control. Electr. Power Syst. Res., vol. 97, pp. 144-150.

[12] V. Kumar, R. R. Joshi, and R. C. Bansal,(2009), Optimal control of matrix-converter-based WECS for performance enhancement and efficiency optimization,. IEEE Trans. Energy Convers., vol. 24, no. 1, pp. 264-273.

[13] M. Komatsu, H. Miyamoto, H. Ohmori, and A. Sano,(2001) , Output maximization control of wind turbine based on extremum control strategy. Proc. 2001 Am. Control Conf., vol. 2, no. 8, pp. 1739-1740.

[14] L. Y. Pao and K. E. Johnson, (2011), Control of Wind Turbines. IEEE Control Syst., vol. 31, no. 2, pp. 44-62.

[15] W. Qiao, W. Zhou, J. M. Aller, and R. G. Harley, (2008) Wind speed estimation based sensorless output maximization control for a wind turbine driving a DFIG. IEEE Trans. Power Electron., vol. 23, no. 3, pp. 1156-1169.

[16] C. Burgos-Mellado et al., (2017), Experimental evaluation of a CPT-based four-leg active power compensator for distributed generation. IEEE J. Emerg. Sel. Top. Power Electron., vol. 5, no. 2 , pp. 747-759.

[17] R. Marino, S. Peresada, and P. Valigi, (1993), Adaptive InputOutput Linearizing Control of Induction Motors. IEEE Trans. Automat. Contr., vol. 38, no. 2, pp. 208-221.

[18] C. Ganesh, S. Anupama, and M. B. H. Kumar, (2016), Control of Wind Energy Conversion System and Power Quality Improvement in the Sub Rated Region Using Extremum Seeking Indonesian Journal of Electrical Engineering and Informatics . vol. 4, no. 1, pp $12-17$.

[19] E. Koutroulis and K. Kalaitzakis,(2006), Design of a maximum power tracking system for wind-energy-conversion applications. IEEE Trans. Ind. Electron., vol. 53, no. 2, pp. 486-494.

[20] C. Ganesh, S. Anupama, and M. B. H. Kumar,(2015), Maximum Power Extraction of Wind Energy Conversion System In The Sub Rated Region Using Extremum Seeking. International Journal of Applied Engineering and Research ,pp. 12-17.

[21] H. Fathabadi, (2016), Novel high efficient speed sensorless controller for maximum power extraction from wind energy conversion systems, Energy Convers. Manag., vol. 123, pp. 392401.

[22] A. Ghaffari, M. Krstic, and S. Sechagiri, (2014) ,Power optimization and control in wind energy conversion systems using extremum seeking. IEEE Trans. Control Syst. Technol., vol. 22, no. 5, pp. 1684-1695.

[23] S. M. Raza Kazmi, H. Goto, H.-J. Guo, and O. Ichinokura, (2011), A Novel Algorithm for Fast and Efficient Speed-Sensorless Maximum Power Point Tracking in Wind Energy Conversion Systems. Ind. Electron. IEEE Trans., vol. 58, no. 1, pp. 29-36.

[24] L. Dusonchet and E. Telaretti,(2011),Effects of electrical and mechanical parameters on the transient voltage stability of a fixed speed wind turbine. Electr. Power Syst. Res., vol. 81, no. 7, pp. 1308-1316.

[25] J. G. Slootweg, S. W. H. de Haan, H. Polinder, and W. L. Kling, (2003), General model for representing variable speed wind turbines in power system dynamics simulations. IEEE Trans. Power Syst., vol. 18, no. 1, pp. 144-151.

[26] J. Rodriguez, M. Rivera, J. W. Kolar, and P. W. Wheeler,(2012), A review of control and modulation methods for matrix converters. IEEE Trans. Ind. Electron., vol. 59, no. 1, pp. 58-70

[27] M. Espinoza, R. Cardenas, M. Diaz, and J. Clare, (2016), An Enhanced dq-Based Vector Control System for Modular Multilevel Converters Feeding Variable Speed Drives. IEEE Trans. Ind.
Electron., pp. 1-1.

[28] W.-L. Chen and Y.-Y. Hsu, (2006), Controller Design for an Induction Generator Driven by a Variable-Speed Wind Turbine. IEEE Trans. Energy Convers., vol. 21, no. 3, pp. 625-635.

[29] L. A. C. Lopes and R. G. Almeida, (2006), Wind-driven selfexcited induction generator with voltage and frequency regulated by a reduced-rating voltage source inverter. IEEE Trans. Energy Convers., vol. 21, no. 2, pp. 297-304.

[30] M. Guay, D. Dochain, and M. Perrier, (2005), Adaptive extremumseeking control of nonisothermal continuous stirred tank reactors. Chem. Eng. Sci., vol. 60, no. 13, pp. 3671-3681. 